\title{
Do white matter changes on MRI and CT differentiate vascular dementia from Alzheimer's disease?
}

\author{
TIMO ERKINJUNTTI, LEENA KETONEN, RAIMO SULKAVA, \\ JORMA SIPPONEN, MATTI VUORIALHO, MATTI IIVANAINEN \\ From the Department of Neurology, Institute of Diagnostic Radiology and MRI Laboratory, University of \\ Helsinki, Helsinki, Finland
}

SUMMARY MRI showed white matter changes in all 29 patients with vascular dementia and in eight out of 22 patients with Alzheimer's disease. The corresponding figures for CT were 26 and 1 , respectively. White matter changes are therefore a useful diagnostic aid in the differential diagnosis between vascular dementia and Alzheimer's disease.

Vascular dementia and Alzheimer's disease are the two main types of dementia. ${ }^{1}$ Neuroradiological differentiation of vascular dementia and Alzheimer's disease has usually focused on differences in cortical and central atrophic changes ${ }^{23}$ and on the presence or absence of infarcts on CT. ${ }^{3-6} \mathrm{CT}$, however, has not differentiated the types of dementia adequately, ${ }^{2-7}$ obviously because white matter changes have often been neglected. Our preliminary experience with MRI showed white matter changes in vascular dementia, but not in Alzheimer's disease. ${ }^{8} \mathrm{~A}$ larger series of consecutive patients with vascular dementia or Alzheimer's disease was studied by MRI and $\mathrm{CT}$ in order to evaluate white matter changes in these types of dementia and the possible usefulness of MRI as their differential diagnostic aid.

\section{Patients and methods}

In the Memory and Dementia Project at the Department of Neurology, University of Helsinki, 233 consecutively admitted patients with dementia were studied from 4 May, 1982 to 31 May, 1985. Alzheimer's disease comprised 68 patients, vascular dementia 133 and secondary causes of dementia 32 patients. From this source population 51 patients, fulfilling the criteria of vascular dementia or Alzheimer's disease, and consecutively studied by both MRI and CT were included in the present study. There were 29 patients with vascular dementia (10 men, 19 women) and 22 patients with Alzheimer's disease (12 men, 10 women). The mean age (mean \pm SEM) was $68.7 \pm 1.7$ years (range 53 to 87 ) in patients

Address for reprint requests: Dr Timo Erkinjuntti, Department of Neurology, University of Helsinki, SF-00290 Helsinki, Finland.

Received 24 January 1986 and in revised.form 16 April 1986. Accepted 25 April 1986. with vascular dementia and 64.0 $\pm 1 \cdot 7$ years (range 50 to 77 ) in those with Alzheimer's disease.

All patients were clinically examined by two neurologists (TE, RS). Diagnostic assessment included detailed medical history, physical and neurological investigation, screening laboratory tests, investigation of the cerebrospinal fluid, neuropsychological test battery, EEG and CT.

The clinical criteria for vascular dementia were: dementia with a history of focal or acute signs or symptoms referable to disturbances in cerebral blood circulation, often with elevated blood pressure, abrupt onset of symptoms, stepwise deterioration and relative preservation of personality. 910 The corresponding criteria for Alzheimer's disease were: dementia with insidious onset and progressive deteriorating course without history, signs or symptoms of focal brain damage and without history or laboratory findings referable to any other aetiology. ${ }^{11}$

Secondary causes of dementia, other than vascular aetiologies, including normal pressure hydrocephalus, ${ }^{12}$ and factors known to give reduction in white matter attenuation on CT, for example, multiple sclerosis and leucodystrophies, ${ }^{14-17}$ were excluded. The CT data together with clinical data were used in the exclusion of secondary causes of dementia.

Dementia was assessed using the Dementia Scale ${ }^{18}$ and a Luria based neuropsychological test battery ${ }^{19}$ according to the DSM III criteria. 9 Dementia was mild in 10 patients with vascular dementia and in 10 patients with Alzheimer's disease, moderate in 13 with vascular dementia and in nine with Alzheimer's disease and severe in six with vascular dementia and in three with Alzheimer's disease. The mean duration ( \pm SEM) of cognitive symptoms was $3.3 \pm 0.5$ years (range 0 to 11 ) in vascular dementia and $4.0 \pm 0.5$ years (range 1 to 9) in Alzheimer's disease.

The Modified Ischemic Score ${ }^{20}$ was also given to the patients. It was $7.3 \pm 0.5$ (mean $\pm S E M$, range 2 to 12 ) in patients with vascular dementia and $0.3 \pm 0.1$ (range 0 to 1 ) in those with Alzheimer's disease $(p<0.001)$. 

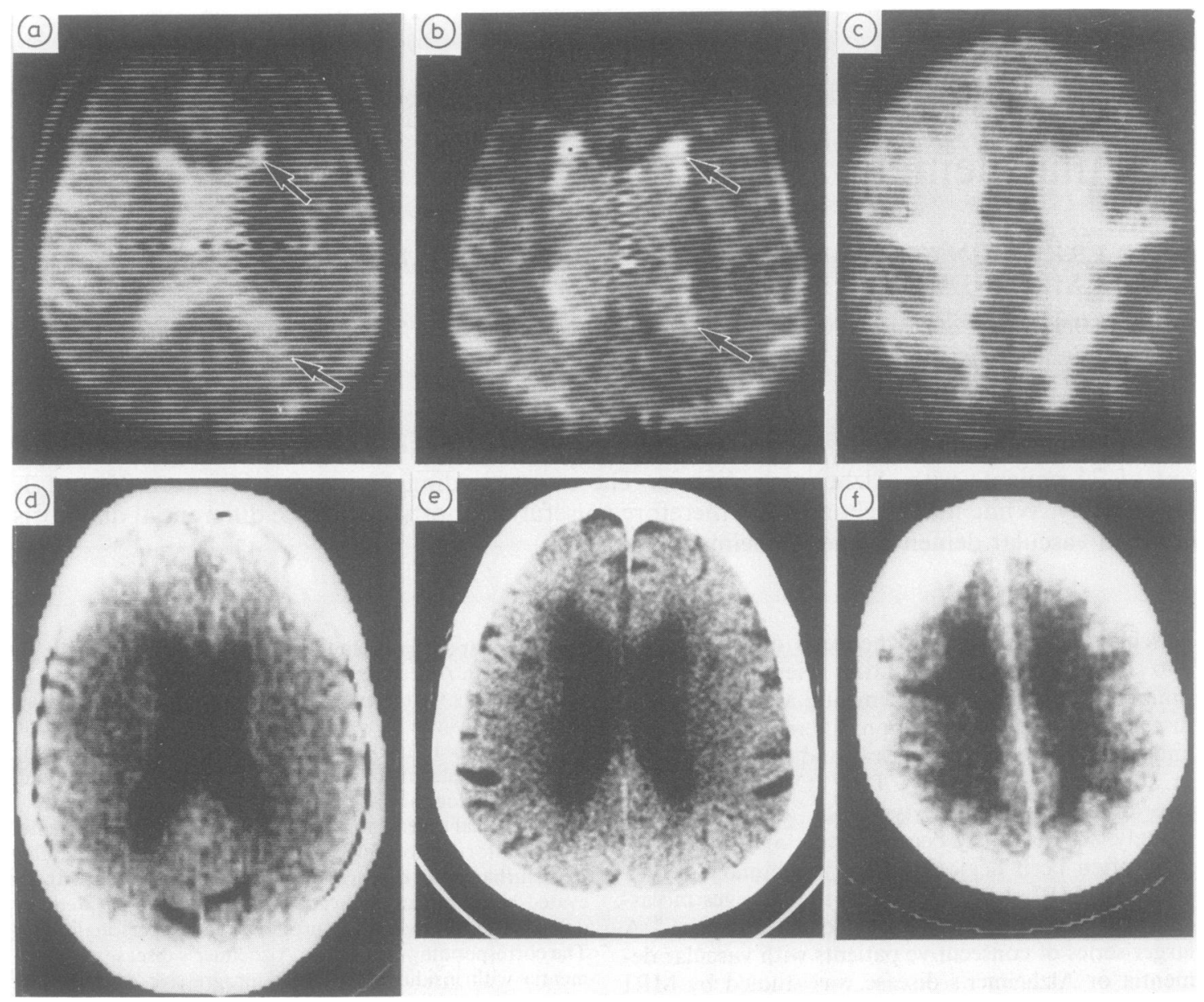

Fig T2 weighted MR image demonstrating mild ( $a$ ) and moderate $(b)$ degree of white matter change around the frontal and occipital horns. The lesion appears as high signal intensity (arrows). Plain CT scans (d,e) with low attenuation in the corresponding areas. T2 weighted MR image ( $c$ ) of a patient with severe white matter change appearing as high signal intensity in the periventricular white matter. Corresponding CT image $(f)$ demonstrates extensive low attenuation in the same area.

MRI was performed using a prototype MRI equipment manufactured by Instrumentarium Corp., Helsinki, Finland. The device operated with a main magnetic field of $0 \cdot 17 \mathrm{~T}$ (corresponding to $7 \cdot 13 \mathrm{MHz}$ ) produced by a superconducting magnet. Axial transverse sections approximately $10 \mathrm{~mm}$ thick were obtained and displayed on a matrix of 128 $\times 128$ pixels. Data acquisition time varied from 3.5 to $9 \mathrm{~min}$. To obtain T1-weighted images, an IR 1500(400)/30 sequence was used and for T2-weighted images, the SE 2000/100 sequence was used. Noncontrast CT was performed with an EMI CT 1010 or Somatom DR2 scanners. The time interval between MRI and CT was less than 3 months and during this time no clinical acute events were permitted.

In the $\mathrm{T} 2$ weighted images white matter changes and areas of increased signal intensity compatible with infarcts were recorded independently by two of us (LK, JS) without knowledge of the clinical diagnosis. Areas of increased signal intensity relative to the rest of the brain, which are presumed to be due to longer $\mathrm{T} 2$, around frontal or occipital horns, or along the bodies of the lateral ventricles were recorded. The lesion was rated to be mild if there was any sign of long T2 in the white matter extending less than one fourth of the total white matter area (fig, a). Changes were rated moderate if long $\mathrm{T} 2$ was up to half of the white matter area (fig, b), and severe if the long T2 extended over one half of the total white matter area (fig, c). On noncontrast CT images the white matter low attenuations and infarcts were rated by two neuroradiologists (LK, MV) using the same criteria (fig, $d-f$ ). Statistical differences between the groups were calculated using the two-tailed $t$ test and chi-square test. The predictive values of diagnostic test were also calculated. $^{21}$ 
Table 1 White matter $(W M)$ changes in vascular dementia (VD) $(n=29)$ and Alzheimer's disease $(A D)(n=22)$ by $M R I$ and $C T$ in different brain regions

\begin{tabular}{|c|c|c|c|c|c|c|c|c|c|c|c|c|}
\hline \multirow{3}{*}{$\begin{array}{l}\text { Grade of } \\
W M \text { changes }\end{array}$} & \multicolumn{4}{|c|}{ Frontal } & \multicolumn{4}{|c|}{ Periventricular } & \multicolumn{4}{|c|}{ Occipital } \\
\hline & \multicolumn{2}{|c|}{$M R I$} & \multicolumn{2}{|l|}{$C T$} & \multicolumn{2}{|c|}{$M R I$} & \multicolumn{2}{|l|}{$C T$} & \multicolumn{2}{|c|}{$M R I$} & \multicolumn{2}{|l|}{$C T$} \\
\hline & $V D$ & $A D$ & $V D$ & $A D$ & $V D$ & $A D$ & $V D$ & $A D$ & $V D$ & $A D$ & $V D$ & $A D$ \\
\hline $\begin{array}{l}\text { None } \\
\text { Mild } \\
\text { Moderate } \\
\text { Severe }\end{array}$ & $\begin{array}{r}0 \\
7 \\
17 \\
5\end{array}$ & $\begin{array}{r}15 \\
5 \\
2 \\
0\end{array}$ & $\begin{array}{r}3 \\
17 \\
8 \\
1\end{array}$ & $\begin{array}{r}21 \\
1 \\
0 \\
0\end{array}$ & $\begin{array}{r}1 \\
10 \\
8 \\
10\end{array}$ & $\begin{array}{r}17 \\
4 \\
1 \\
0\end{array}$ & $\begin{array}{r}14 \\
6 \\
8 \\
1\end{array}$ & $\begin{array}{r}22 \\
0 \\
0 \\
0\end{array}$ & $\begin{array}{r}2 \\
8 \\
11 \\
8\end{array}$ & $\begin{array}{r}19 \\
3 \\
0 \\
0\end{array}$ & $\begin{array}{r}6 \\
13 \\
9 \\
1\end{array}$ & $\begin{array}{r}21 \\
1 \\
0 \\
0\end{array}$ \\
\hline
\end{tabular}

Table 2 Cerebral infarcts and white matter (WM) changes in vascular dementia (VD) and Alzheimer's disease (AD) by $M R I$ and $C T$

\begin{tabular}{|c|c|c|c|c|c|c|c|c|c|c|c|c|}
\hline & \multicolumn{4}{|c|}{ Infarcts } & \multicolumn{4}{|c|}{$W M$ changes } & \multicolumn{4}{|c|}{ Infarcts or $W M$ changes } \\
\hline & \multicolumn{2}{|c|}{$M R I$} & \multicolumn{2}{|l|}{$C T$} & \multicolumn{2}{|c|}{$M R I$} & \multicolumn{2}{|l|}{$C T$} & \multicolumn{2}{|c|}{$M R I$} & \multicolumn{2}{|l|}{$C T$} \\
\hline & $V D$ & $A D$ & $V D$ & $\overline{A D}$ & $V D$ & $A D$ & $V D$ & $A D$ & $\overline{V D}$ & $A D$ & $\overline{V D}$ & $A D$ \\
\hline $\begin{array}{l}\text { No } \\
\text { Yes }\end{array}$ & $\begin{array}{l}10 \\
19\end{array}$ & $\begin{array}{r}22 \\
0\end{array}$ & $\begin{array}{l}11 \\
18\end{array}$ & $\begin{array}{r}22 \\
0\end{array}$ & $\begin{array}{r}0 \\
29\end{array}$ & $\begin{array}{r}14 \\
8\end{array}$ & $\begin{array}{r}3 \\
26\end{array}$ & $\begin{array}{r}21 \\
1\end{array}$ & $\begin{array}{r}0 \\
29\end{array}$ & $\begin{array}{r}14 \\
8\end{array}$ & $\begin{array}{r}1 \\
28\end{array}$ & 21 \\
\hline
\end{tabular}

Table 3 Sensitivity, specificity, positive and negative predictive values (\%) of white matter (WM) changes on MRI and CT in the diagnosis of vascular dementia. A: no vs. slight to severe WM changes, B: no and slight vs. moderate and severe WM changes*

\begin{tabular}{|c|c|c|c|c|c|c|}
\hline & \multicolumn{2}{|c|}{ Frontal $W M$} & \multicolumn{2}{|c|}{ Periventricular $W M$} & \multicolumn{2}{|c|}{ Occipital $W M$} \\
\hline & $M R I$ & $C T$ & $M R I$ & $C T$ & $M R I$ & $C T$ \\
\hline $\begin{array}{l}\text { A. } \\
\text { Sensitivity } \\
\text { Specificity } \\
\text { Positive predictive value } \\
\text { Negative predictive value } \\
\text { B. }\end{array}$ & $\begin{array}{r}100 \cdot 0 \\
68 \cdot 2 \\
80 \cdot 6 \\
100 \cdot 0\end{array}$ & $\begin{array}{l}89 \cdot 7 \\
95 \cdot 5 \\
96 \cdot 3 \\
87 \cdot 5\end{array}$ & $\begin{array}{l}96 \cdot 6 \\
77 \cdot 3 \\
84 \cdot 8 \\
94 \cdot 4\end{array}$ & $\begin{array}{r}51 \cdot 7 \\
100 \cdot 0 \\
100 \cdot 0 \\
61 \cdot 1\end{array}$ & $\begin{array}{l}93 \cdot 1 \\
86 \cdot 4 \\
90 \cdot 0 \\
90 \cdot 5\end{array}$ & $\begin{array}{l}79 \cdot 3 \\
95 \cdot 5 \\
95 \cdot 8 \\
77 \cdot 8\end{array}$ \\
\hline $\begin{array}{l}\text { Sensitivity } \\
\text { Specificity } \\
\text { Positive predictive value } \\
\text { Negative predictive value }\end{array}$ & $\begin{array}{l}75 \cdot 9 \\
90 \cdot 9 \\
91 \cdot 7 \\
74 \cdot 1\end{array}$ & $\begin{array}{r}31 \cdot 0 \\
100 \cdot 0 \\
100 \cdot 0 \\
52 \cdot 4\end{array}$ & $\begin{array}{l}62 \cdot 1 \\
95 \cdot 5 \\
94 \cdot 7 \\
65 \cdot 6\end{array}$ & $\begin{array}{r}31 \cdot 0 \\
100 \cdot 0 \\
100 \cdot 0 \\
52 \cdot 4\end{array}$ & $\begin{array}{r}65 \cdot 5 \\
100 \cdot 0 \\
100 \cdot 0 \\
68 \cdot 8\end{array}$ & $\begin{array}{r}34 \cdot 5 \\
100 \cdot 0 \\
100 \cdot 0 \\
53 \cdot 7\end{array}$ \\
\hline
\end{tabular}

*Computed from data given in table 1.

Table 4 Sensitivity, specificity, positive predictive values (\%) and negative predictive values (\%) of infarcts and white matter (WM) changes on MRI and CT in the diagnosis of vascular dementia*

\begin{tabular}{|c|c|c|c|c|c|c|}
\hline & \multicolumn{2}{|c|}{ Infarcts } & \multicolumn{2}{|c|}{$W M$ changes } & \multicolumn{2}{|c|}{ Infarcts or $W M$ changes } \\
\hline & $M R I$ & $C T$ & $M R I$ & $C T$ & $M R I$ & $C T$ \\
\hline $\begin{array}{l}\text { Serısitivity } \\
\text { Specificity } \\
\text { Positive predictive value } \\
\text { Negative predictive value }\end{array}$ & $\begin{array}{r}65 \cdot 5 \\
100 \cdot 0 \\
100 \cdot 0 \\
68 \cdot 8\end{array}$ & $\begin{array}{r}62 \cdot 1 \\
100 \cdot 0 \\
100 \cdot 0 \\
66 \cdot 7\end{array}$ & $\begin{array}{r}100 \cdot 0 \\
63 \cdot 3 \\
78 \cdot 4 \\
100 \cdot 0\end{array}$ & $\begin{array}{l}89 \cdot 7 \\
95 \cdot 5 \\
96 \cdot 3 \\
87 \cdot 5\end{array}$ & $\begin{array}{r}100 \cdot 0 \\
63 \cdot 6 \\
78 \cdot 4 \\
100 \cdot 0\end{array}$ & $\begin{array}{l}96 \cdot 6 \\
95 \cdot 5 \\
96 \cdot 6 \\
95 \cdot 5\end{array}$ \\
\hline
\end{tabular}

* Computed from data given in table 2.

\section{Results}

White matter changes on MRI and CT are shown in table 1. On MRI white matter changes were detected in all patients with vascular dementia, but only in eight patients with Alzheimer's disease. The degree of the white matter changes was moderate to severe in vascular dementia, while it was mostly mild in Alzheimer's disease. MRI was more sensitive to detect white matter changes than $\mathrm{CT}$.
White matter changes and areas of altered signal compatible with cerebral infarcts as seen on MRI and CT are shown in table 2 . Nineteen $(65.5 \%)$ of the patients with vascular dementia had infarcts on MRI and $18(62.0 \%)$ on $\mathrm{CT}$, while none of the patients with Alzheimer's disease had infarcts on MRI or CT. Infarcts or white matter changes were seen in all of the 29 patients with vascular dementia on MRI and in 28 on CT. One patient with vascular dementia who had no vascular changes on CT at the time of in- 
Table 5 White matter (WM) changes among patients with Alzheimer's disease $(A D)(n=22)$ and vascular dementia (VD) $(n=29)$ on MRI and $C T$ by age $(A)$ and severity of dementia $(B)$

\begin{tabular}{|c|c|c|c|c|c|c|c|c|}
\hline & \multicolumn{4}{|c|}{$M R I$} & \multicolumn{4}{|l|}{$C T$} \\
\hline & \multicolumn{2}{|l|}{$V D$} & \multicolumn{2}{|l|}{$A D$} & \multicolumn{2}{|l|}{$V D$} & \multicolumn{2}{|l|}{$A D$} \\
\hline & Yes & No & Yes & No & Yes & No & Yes & No \\
\hline $\begin{array}{l}\text { A. Age group } \\
<60 \text { years } \\
60-70 \text { years } \\
>70 \text { years } \\
\text { B. Severity of dementia }\end{array}$ & $\begin{array}{r}6 \\
6 \\
17\end{array}$ & $\begin{array}{l}0 \\
0 \\
0\end{array}$ & $\begin{array}{l}1 \\
2 \\
5\end{array}$ & $\begin{array}{l}6 \\
6 \\
2\end{array}$ & $\begin{array}{r}4 \\
6 \\
16\end{array}$ & $\begin{array}{l}2 \\
0 \\
1\end{array}$ & $\begin{array}{l}0 \\
0 \\
1\end{array}$ & $\begin{array}{l}7 \\
8 \\
6\end{array}$ \\
\hline $\begin{array}{l}\text { Mild } \\
\text { Moderate } \\
\text { Severe }\end{array}$ & $\begin{array}{r}10 \\
13 \\
6\end{array}$ & $\begin{array}{l}0 \\
0 \\
0\end{array}$ & $\begin{array}{l}4 \\
4 \\
0\end{array}$ & $\begin{array}{l}6 \\
5 \\
3\end{array}$ & $\begin{array}{r}8 \\
12 \\
6\end{array}$ & $\begin{array}{l}2 \\
1 \\
0\end{array}$ & $\begin{array}{l}0 \\
1 \\
0\end{array}$ & $\begin{array}{r}10 \\
8 \\
3\end{array}$ \\
\hline
\end{tabular}

vestigation developed an infarct visible on $\mathrm{CT}$ three months later.

The presence or absence of white matter changes and infarcts on MRI and CT were further evaluated by calculating sensitivity, specificity, positive and negative predictive values of these changes in the diagnosis of vascular dementia (tables 3 and 4). Frontal white matter changes were most sensitive, while occipital changes were most specific. If mild white matter changes were used as a positive indicator of vascular dementia, MRI gave high sensitivity, but lower specificity. On the other hand, CT gave better specificity but lower sensitivity. If only moderate to severe white matter changes were regarded to be indicative of vascular dementia, the specificity improved at the cost of sensitivity. Infarcts gave better specificity but lower sensitivity than gave white matter changes alone or combined with infarcts. Either white matter changes or infarcts as an indicator of vascular dementia on CT gave good sensitivity $(97 \%)$ and specificity $(96 \%)$. On MRI these changes, however, did not give a better discriminative power than the white matter changes alone (sensitivity $100 \%$, specificity $63 \%$ ).

White matter changes on MRI and CT by age and severity of dementia are given in table 5 . The number of patients with white matter changes increased with age (MRI: $\chi^{2}=8.36, p=0.015 ;$ CT: $\chi^{2}=6.22, p=$ 0.045 ), but not with the severity of dementia.

\section{Discussion}

All the 29 patients with vascular dementia had white matter changes on MRI, while 26 of them showed changes on CT. Eight of the 22 patients with Alzheimer's disease had white matter changes on MRI, and only one on CT. White matter changes in Alzheimer's disease were mostly mild. The eight Alzheimer patients with white matter changes were older and had dementia of mild to moderate degree. Compared to CT, MRI was more sensitive to reveal white matter changes both in vascular dementia and Alz- heimer's disease. It especially gave a good contrast on the T2-weighted MRI, as noted also previously. ${ }^{81722}$ The overall correlation between MRI and CT was good. Detection of white matter changes is better with the high resolution CT scanner, but comparisons between the two CT scanners used in the present study were not made in detail. The same is true with the MR imagers with thinner sections and better spatial resolution.

None of the Alzheimer patients showed infarcts on MRI or CT. Of the patients with vascular dementia $19(65.5 \%)$ had infarcts on MRI and $18(62.0 \%)$ on CT. These figures are higher than in previous studies where the corresponding figures on CT varied from $26 \%$ to $42 \% .^{3-6}$ The appearance of white matter changes or infarcts on MRI and on CT in the present series suggests that MRI is more sensitive than CT to demonstrate these changes.

White matter changes have been described previously in disorders related to different types of vascular dementia including Binswanger's disease, the lacunar state, systemic hypoperfusion and multiple strokes. ${ }^{81723-27}$ In this study all patients with vascular dementia had white matter changes. The loss of total brain volume due to infarcts in vascular dementia has been emphasised in the development of the dementia syndrome. ${ }^{28}$ However, our present experience suggests that also disconnection to the cortex due to white matter changes may give rise to symptoms of vascular dementia.

In our preliminary report of three presenile $\mathrm{Alz}$ heimer patients we did not find any white matter changes either on CT or on MRI, ${ }^{8}$ but in the present larger series we found mild to moderate white matter changes in some Alzheimer patients. Loss of graywhite matter discriminability ${ }^{29}$ and decreased white matter parenchymal density, with no clear white matter low attenuation, have been reported on CT of patients with Alzheimer's disease. ${ }^{30}$ Decreased white matter density, however, was not confirmed by Gado et al. ${ }^{31}$ Previously MRI was used in the differentiation between vascular dementia and Alz- 
heimer's disease. ${ }^{32}$ In that study proton density values in white matter were lower in vascular dementia than in Alzheimer's disease while $\mathrm{T} 1$ values were equally lowered in both types of dementia. However, T2 values, which were more informative in our present study, were not used. Therefore, our results are not comparable with those of Besson et al..$^{32}$

Some white matter changes might be age related. Zatz et $a l^{33}$ reported decreased attenuation values of the white matter on CT in normal elderly people. However, no clear focal or generalised low attenuation of white matter was noted. Young et al pointed out that small areas of long T2 around the frontal horns might be normal. ${ }^{16}$ In our series the occurrence of white matter changes increased with age but not with the severity of dementia. Thus the mild white matter changes among Alzheimer patients may be partly age related. White matter changes among the patients with mild to moderate Alzheimer's disease may also be related to minor ischaemic events. ${ }^{2834} \mathrm{~A}$ further possibility is that these older Alzheimer patients with white matter changes on MRI constitute its own diagnostic entity. ${ }^{35}$

In conclusion, white matter changes as seen on MRI and also on CT are a useful aid in the differential diagnosis between the two main types of dementia: vascular dementia and Alzheimer's disease.

We thank the University Central Hospital, Helsinki, and the Academy of Finland for the financial support, and the nursing and technical staff of the Department of Neurology, Institute of Diagnostic Radiology and MRI Laboratory, University of Helsinki, for their skilful assistance.

\section{References}

1 Sulkava R, Wikström J, Aromaa A, et al. Prevalence of severe dementia in Finland. Neurology 1985;35: 1025-9.

2 de Leon MJ, George AE. Computed tomography in aging and senile dementia of the Alzheimer type. In: Mayeux R, Rosen WG. The Dementias. New York: Raven Press, 1983:103-22.

3 Soininen H, Puranen M, Riekkinen PJ. Computed tomography findings in senile dementia and normal aging. J Neurol Neurosurg Psychiatry 1982;45:50-4.

4 Radue E-W, du Boulay GH, Harrison MJG, Thomas DJ. Comparison of angiographic and CT findings between patients with multi-infarct dementia and those with dementia due to primary neuronal degeneration. Neuroradiology 1978;16:113-5.

5 Roberts MA, McGeorge AP, Caird FI. Electroencephalography and computerised tomography in vascular and non-vascular dementia in old age. $J \mathrm{Neu}$ rol Neurosurg Psychiatry 1978;41:903-6.

6 Kohlmeyer K. Vascular (multi-infarct) dementia versus primarily degenerative (Alzheimer's) dementia: A study of rCBF and computed tomography (CT). Exp Brain Res 1982;5 (suppl):201-7.

7 Wilson RS, Fox JH, Huckman MS, Bacon LD, Lobick JJ. Computed tomography in dementia. Neurology 1982;32:1054-7.

8 Erkinjuntti T, Sipponen JT, livanainen M, Ketonen L, Sulkava R, Sepponen RE. Cerebral NMR and CT imaging in dementia. J Comput Assist Tomogr 1984; 8:614-8.

9 American Psychiatric Association. Diagnostic and statistical manual of mental disorders. 3rd ed. Washington, DC: American Psychiatric Association, 1980.

10 Roth $M$. The natural history of mental disorder in old age. J Ment Sci 1955;101:281-301.

11 McKhann G, Drachman D, Folstein M, Katzman R, Price D, Stadlan EM. Clinical diagnosis of Alzheimer's disease: Report of the NINCDS-ADRDA Work Group under the auspices of Department of Health and Human Services Task Force on Alzheimer's disease. Neurology 1984;34:939-44.

12 Barret RE. Dementia in adults. Med Clin North Am 1972;56:1405-18.

13 Di Chiro G, Arimitsu T, Brooks RA, et al. Computed tomography profiles of periventricular hypodensity in hydrocephalus and leucoencephalopathy. Radiology 1979;130:661-6.

14 Valentine AR, Moseley IF, Kendall BE. White matter abnormality in cerebral atrophy: clinicoradiological correlations. J Neurol Neurosurg Psychiatry 1980; 43:139-42.

15 Heinz ER, Drayer BP, Haenggeli CA, Painter MJ, Crumrine P. Computed tomography in white-matter disease. Radiology 1979;130:371-8.

16 Young IR, Randell CP, Kaplan PW, James A, Bydder GM, Steiner RE. Nuclear magnetic resonance (NMR) imaging in white matter disease of the brain using spin-echo sequences. J Comput Assist Tomogr 1983; 7:290-4.

17 Bydder GM, Steiner RE, Young IR, et al. Clinical NMR imaging of the brain: 140 cases. AJR 1982;139:215-36.

18 Blessed G, Tomlinson BE, Roth $M$. The association between quantitative measures of dementia and of senile change in the cerebral grey matter of elderly subjects. Br J Psychiatry 1968;114:797-811.

19 Laaksonen R, Erkinjuntti T, Granberg M, Amberla K, Sulkava R. D-test battery-a comprehensive neuropsychological screening test. Preliminary results. Reports of Psychiatria Fennica 1985;63:87-94.

20 Rosen WG, Terry RD, Fuld PA, Katzman R, Peck A. Pathological verification of ischemic score in differentiation of dementias. Ann Neurol 1980;7:486-8.

21 Vecchio TJ. Predictive value of a single diagnostic test in unselected populations. $N$ Engl J Med 1966;274: 1171-3.

22 Kinkel WR, Jacobs L, Polachini I, Bates V. NMR abnormalities in extracranial occlusive cerebrovascular disease not seen by CT. Neurology 1984;34 (suppl 1): 201.

23 Rosenberg GA, Kornfeld M, Stovring J, Bicknell JM. Subcortical arteriosclerotic encephalopathy (Binswanger): Computerized tomography. Neurology 1979;29:1102-6.

24 Wodarz $\mathbf{R}$. Watershed infarctions and computed tom- 
ography. A topographical study in cases with stenosis or occlusion of the carotid artery. Neuroradiology 1980;19:245-8.

25 Loizou LA, Kendall BE, Marshall J. Subcortical arteriosclerotic encephalopathy: a clinical and radiological investigation. J Neurol Neurosurg Psychiatry 1981; 44:294-304.

26 Pullicino P, Eskin T, Ketonen L. Prevalence of Binswanger's disease. Lancet 1983;i:939.

27 De Witt LD, Buonanno FS, Kistler JP, et al. Nuclear magnetic resonance imaging in evaluation of clinical stroke syndromes. Ann Neurol 1984;16:535-45.

28 Tomlinson BE, Blessed G, Roth M. Observations of the brains of demented old people. J Neurol Sci 1970;11: 205-42.

29 George AE, de Leon MJ, Ferris SH, Kricheff II. Parenchymal CT correlates of senile dementia (Alzheimer's disease): Loss of gray-white matter discriminability. AJNR 1981;2:205-13.

30 Naeser MA, Gebhardt C, Levine HL. Decreased computerized tomography numbers in patients with pre- senile dementia. Detection in patients with otherwise normal scans. Arch Neurol 1980;37:401-9.

31 Gado M, Danziger WL, Chi D, Hughes CP, Cobem LA. Brain parenchymal density measurements by CT in demented subjects and normal controls. Radiology 1983;147:703-10.

32 Besson JAO, Corrigan FM, Foreman EI, Ashcroft GW, Eastwood LM, Smith FW. Differentiating senile dementia of Alzheimer type and multi-infarct dementia by proton NMR imaging. Lancet 1983;ii:789.

33 Zatz LM, Jernigan TL, Ahumada AJ. White matter changes in cerebral computed tomography related to aging. J Comput Assist Tomogr 1982;6:19-23.

34 Brun A, Englund E. Alzheimer type dementia and white matter changes. Acta Neurol Scand 1985;71:87-8.

35 Gottfries CG, Karlsson I, Svennerholm L. Senile dementia-a "white matter" disease? In: Gottfries CG, ed. Normal Aging, Alzheimer's Disease and Senile Dementia. Aspects on Etiology, Pathogenesis, Diagnosis and Treatment. Bruxelles: Editions de l'universite de Bruxelles, 1985:111-8. 